\title{
Being religious implies being different in humour: evidence from self- and peer-ratings
}

\author{
VASSILIS SAROGLOU \\ Université catholique de Louvain, Department of Psychology, Centre for Psychology of Religion, \\ Belgium
}

\begin{abstract}
Previous research indicated negative associations between religiosity and humour creation and appreciation. The present studies on 175 students (study 1) and 196 adults from married couples (study 2) investigated the links between religiosity and spirituality and the use of specific humour styles (assessed on the basis of Martin et al. (2003) Humor Styles Questionnaire and Craik et al. (1996) Humorous Behavior Q-Sort Deck). In study 1 (self-reports), men's spirituality and religiosity were found to be negatively related respectively to the use of hostile and social humour. In study 2 (self-and/or spouse-ratings), there was weak but meaningful evidence that both religious men and women did not tend to use hostile and earthy humour nor, to some extent, social humour. Religious men tended to use self-defeating humour, a finding partially due to their high insecurity in attachment. Moreover, religiosity and/or spirituality was found to be related to between-spouse similarity in many humour styles. The discussion points out the willingness of religious people to share similar values and ways of enjoyment with their partners as well as the fact that the 'discomfort' of religion with humour seems to encompass a large number of humour styles.
\end{abstract}

\section{Introduction}

Is there a 'discomfort' of religion with humour? There is historical evidence that this is the case (Gilhus, 1997). It has been recently suggested that, from a psychological perspective, this discomfort, far from being a historical 'accident', reflects a deeper dimension of religion (see Saroglou, 2002a). Humour entails playing on meaning, openness to the possibility of a meaningless world, introduction of disorder, and transgression of societal norms; it implies surprise, loss of control, openness to novelty and ambiguity, and disengagement with regard to truth, morality, and affection. Religion, on the other hand, although

Correspondence to: Dr Vassilis Saroglou, Université catholique de Louvain, Faculty of Psychology and Educational Sciences, Place du Cardinal Mercier 10, B-1348 Louvain-la-Neuve, Belgium. E-mail: Vassilis.Saroglou@psp.ucl.ac.be 
it shares with humour a willingness for an alternative perception of reality (Berger, 1997), it also emphasizes the meaningfulness of the world, order and structure in life and closure in cognition, need for control, discomfort with ambiguity and novelty, as well as engagement with regard to truth, morality, and interpersonal relations.

Recent empirical evidence supports the idea that individual differences in specific humour performances are, to some extent, a function of religiosity. Indeed, people high in religious fundamentalism but also high in religiosity per se, although they did not tend to report low sense of humour or use of humour as coping, were found to produce low spontaneous humour when faced with hypothetical daily hassles (Saroglou, 2002b). In addition, exposure to religious stimulation in laboratory reduces spontaneous humour created in reaction to the same hypothetical daily hassles (Saroglou \& Jaspard, 2001). Yet, the above results should not be interpreted as resulting from an inability of religious people to find some situations or stimuli humorous, but from a possible need for self-control. Indeed, religious people did not tend to produce humour in the condition of religious stimulation nor in the control condition of no specific stimulation, but there was no longer a negative correlation between religiousness and humour creation when participants were exposed to humorous stimulation (Saroglou \& Jaspard, 2001).

Little is known, however, on how people's religiosity is associated, not with humour in general, but with specific humour styles. In a previous study, Saroglou (2003) found that students high in religious fundamentalism and orthodoxy do not tend to appreciate humour in general, nor two different styles in particular: humour where incongruity is resolved, and nonsense humour, where incongruity remains unresolved. The association between religiosity and appreciation of the third type included in the measure used (3 Witz-Dimensionen Humor Test; see Ruch, 1992), that is sexual humour, was also negative although not significant. However, this study presents some limitations. First, appreciation of different humour styles is somewhat different from the use of specific humour styles (see Köhler \& Ruch, 1996; Thorson \& Powell, 1993, for differences between appreciation and creation of humour in general). Second, the three styles included in the measure used do not represent a broad spectrum of humour styles, which can differ in their content and the emotional affect associated with this content as well as in their pro-, a-, or anti-social character.

It is therefore important to investigate how religiosity is related to the use of specific humour styles focusing on particular topics (for example, sick humour, racist humour, ethnic jokes) or reflecting special attitudes towards others (for example, hostile humour, social humour). Beyond that, rather than a general 'discomfort' of religion with humour, one can suspect a discomfort with some specific styles of humour. The aim of the present study was then to investigate this question.

The present study was facilitated by the recent development of two measures of different humour styles. Craik et al. (1996) Humorous Behavior Q-Sort Deck (HBQD) distinguishes between five bipolar humorous conducts: socially warm 
versus cold, reflective versus boorish, competent versus inept, earthy versus repressed, and benign versus mean-spirited humour. Martin et al. (2003) Humor Styles Questionnaire (HSQ) distinguishes between four humour styles: sociallaffiliative, self-enhancing, self-defeating, and hostile humour.

We investigated in two studies whether religiosity was associated with specific humour styles. We hypothesized first that religiosity is negatively correlated with the use of hostile humour. Hostility and aggression, whether direct or indirect, are condemned by all religious traditions, and one of the most systematic traits of the religious personality is high prosociality: high Agreeableness (Saroglou, 2002c), low Psychoticism (Eysenck, 1998), and high self-reported altruistic behaviour (Batson et al., 1993).

Second, religiosity was hypothesized to be negatively related to the use of earthy humour. Laughing at macabre, scatological, sexual, and vulgar topics may make religious people feel uncomfortable. The obsessive character of religious people (in terms of traits and not symptoms; see Lewis, 1998, for review) could prevent them from being comfortable with situations of disorder and disruption of harmony such as those produced by death, decomposition, and other disgusting matters. Need for purity can also include, at least to some extent, sexuality. Overall, earthy humour constitutes an important form of transgression of established norms and, as such, may only be rarely used by religious people because of the tendency of the latter to social conformity and conservatism in values (Schwartz \& Huismans, 1995), political and social attitudes, and sexual practices (Wulff, 1997).

Third, social humour and use of humour as coping mechanism seem to constitute the typical humour styles that reflect an overall sense of humour (Craik et al., 1996; Martin et al., 2003; Ruch, 1994). We hypothesized then, on the basis of the theoretical considerations presented above, that if an association exists between religion and use of these styles, it should be negative. However, the sociability component of social humour could attenuate the hypothesized negative association because, as mentioned above, there is a stable connection between religion and prosocial dimensions of personality.

Fourth, self-defeating humour, that is, using humour in an excessively selfdisparaging way and thus preserving inclusion in the group (see Martin et al., 2003), is known to reflect emotional instability, anxiety, and insecure attachment in childhood, as well as low self-esteem, well-being and social intimacy (Martin et al., 2003; Saroglou and Scariot, 2002). We hence hypothesized that this humour style is unrelated to religion. Overall, religiosity per se, that is, without distinguishing between specific religious dimensions, is unrelated to Neuroticism, both in terms of Eysenck's model (Eysenck, 1998) and the Big Five model (Saroglou, 2002c), and it is even positively related with subjective well-being (Diener et al., 1999) and self-esteem (Koenig et al., 2000). In addition, associations of religion with security in attachment are complex and depend on the type of religiosity (security for socialization-based religion versus insecurity for emotion-based religion), method of collecting data (security for cross-sectional versus insecurity for longitudinal data), type of attachment measure (one-item 
descriptions versus multi-item scales), and object of attachment (parental versus adult) (Granqvist \& Hagekull, 1999; Kirkpatrick, 1999; Saroglou et al., 2003).

Finally, competence in humour, that is, creativity in spontaneous humour production rather than re-production and easiness in repartee, was expected to be unrelated to religion. A recent review suggests that religiosity is unrelated to intelligence (Francis, 1998). Moreover, religiosity is unrelated to Openness to Experience (Saroglou, 2002c), a personality dimension of the Big Five Model that is determinant for creativity (Simonton, 2002).

Overall, we did not expect large effect sizes. The above empirical evidence on religion and humour indicates small effect sizes, and the contemporary attitude towards humour in many religious traditions is not negative and may rather be considered as valuing humour in spirituality and religious life (for example, Hyers, 1996; Kuschel, 1994). In addition, the mean effect sizes of the personality correlates of religion are clear but modest (Saroglou, 2002c).

The first study focused on the use of humour styles as a function of religiosity among young students. As gender differences could be expected in both humour and religion, we included both men and women in the sample. Students were administered the HSQ and were then asked to provide a self-evaluation of their use of four humour styles: social, self-enhancing, self-defeating, and hostile humour. The second study focused on the use of humour as a function of religion in adults from married couples. Each partner provided an evaluation of individual humour styles as well as an estimation of the spouse's humour styles. Six humour styles were measured: social, coping, hostile, earthy, self-defeating, and competent (items from the HSQ and HBQD). Given the design adopted (both spouses evaluated their own and their partner's humour), the links between religion and use of humour styles were investigated on the basis of both self- and peer (spouse)-ratings. As peer-validation of self-reported personality correlates of religiosity is rare (see Saroglou \& Fiasse, 2003, for an exception), the confrontation between the two ways of measuring humour styles was particularly intriguing, especially when taking into account that humour is a highly socially desirable trait and that religiosity is weakly yet often related to social desirability (Trimble, 1997, for review; but see Lewis, 2000). Finally, in this second study, a measure of attachment was used, because previous evidence suggested that self-defeating humour reflects insecurity in attachment (Saroglou \& Scariot, 2002).

\section{Study 1}

\section{Method}

Participants were 175 high school $(51.9 \%$; age range $=16-18)$ and university (48.1\%; age range $=17-22$ ) students from Belgian (French-speaking) educational institutions. Fifty-three of them were young men and 122 young women. They took part in a large study on cognitive, affective, personality, and 
educational correlates of different humour styles. They were administered the French version (see Saroglou \& Scariot, 2002, for cross-cultural validation) of the original English-Canadian Martin et al. (2003) Humor Styles Questionnaire, a 32-item measure of four humour styles: social, self-enhancing (very similar to the use of humour as coping), hostile, and self-defeating humour (eight items for each style). Participants marked their agreement in a seven-point Likert scale. Typical examples of the statements are: 'I enjoy making people laugh'; 'I don't often joke around with my friends' (social); 'If I am feeling depressed, I can usually cheer myself up with humour'; 'If I am feeling upset or unhappy, I usually try to think of something funny about the situation to make myself feel better' (self-enhancing); 'If I don't like someone, I often use humour or teasing to put them down'; 'If someone makes a mistake, I will often tease them about it' (hostile); 'I will often get carried away in putting myself down if it makes my family or friends laugh'; 'I often try to make people like or accept me more by saying something funny about my own weaknesses, blunders, or faults' (selfdefeating). In addition, a three-item religiosity index (importance of God in life, importance of religion in life, and frequency of prayer; $\alpha=0.87$ ) was used, as well as a one-item index of importance of spirituality in life (seven-point Likert scales ranging from not at all important to very important and, for prayer, a five-point scale from never to almost every day).

\section{Results}

Correlations between religiosity, spirituality and women's humour styles did not reveal any association between religion measures and humour styles. However, men scoring high in importance of spirituality tended to report low use of hostile humour $(r=-0.26, p<0.05)$. In addition, men's religiosity was negatively related to use of social humour $(r=-0.20, p<0.10)$. No other significant associations were found with regard to men's humour and religiosity.

\section{Study 2}

\section{Method}

Participants. The present data are part of a large study investigating how partners' humour styles (measured via both self- and spouse-ratings) and between-spouse similarity - real and perceived-on humour styles were related to quality of attachment and marital satisfaction. Ninety-eight married heterosexual couples (total $n=196$ ) living in urban areas in the French-speaking part of Belgium accepted to participate in this study, the aim of which was presented as: 'to explore different dimensions of family life, i.e. different aspects of partners' relationships, including humour'. Two conditions were respected in selecting couples: at least one of the partners should have a job and the age of participants 
should not be higher than 65 . The age of participants ranged from 26 to 62 years of age $(M=45.8 ; S D=8.7)$ and the mean duration of marriage was 19.5 years. They were asked to fill in the protocols anonymously and separately and to send them back in four to six weeks. People were thanked for their participation and provided with the possibility to be informed of the results if they wished.

\section{Measures}

Humour styles. In order to have a scale encompassing a maximum number of different humour styles without being too long (since each participant had to evaluate individual and spouse's humour), we mixed up styles and corresponding items from the two recent measures of humour styles: Craik et al. (1996) Humorous Behavior Q-Sort Deck (HBQD) and Martin et al. (2003) Humor Styles Questionnaire (HSQ), and we also included items from the Coping Humor Scale (CHS; Martin \& Lefcourt, 1983). Because of their conceptual overlap, we decided to mix up the ten (five, four, and one, respectively) styles of these three scales into six humour styles: social humour (use of humour to amuse others, laugh with others); competent humour (creativity in spontaneous humour production rather than re-production, easiness in repartee); hostile humour (use of humour to attack, offend, and belittle others); earthy humour (delight and non-inhibition in joking about taboo topics: macabre, sexual, scatological, vulgar); self-defeating humour (using humour in an excessively self-disparaging way and thus preserving inclusion in the group); and use of humour as a coping mechanism. The whole scale was composed of 28 items, and four to six items represented each of the six styles. Psychometric characteristics of this composite measure can be seen in Saroglou and Lacour (2003). Rating answers ranged from one (does not characterize me at all) to five (characterizes me absolutely). A self- and a peer (spouse)-version were administered to each participant.

Examples of the statements for social, hostile, and self-defeating humour were presented in Study 1. Examples of items from other humour styles were: 'I have a reputation for indulging in coarse or vulgar humour'; 'I relish in scatological anecdotes' (earthy humour); 'I manifest humour in the form of clever retorts to others' remarks'; 'I am more responsive to spontaneous humour than to jokes' (competent humour); 'If I am feeling upset or unhappy, I usually try to think of something funny about the situation to make myself feel better'; 'I often lose my sense of humour when I'm having problems' (use of humour as coping).

Attachment dimensions. Brennan et al. (1998) Experiences in Close Relationships (ECR) measure is a seven-point Likert-format scale of 36 items measuring two orthogonal dimensions of adult attachment: anxiety and avoidance. The scale is based on analyses of previous attachment scales and taps the underlying structure of these measures corresponding to two orthogonal axes: anxiety about self and 
discomfort with contact with others. The ECR has higher psychometric qualities in comparison with previous multi-item attachment scales (Fraley et al., 2000) and the two-factor structure in our French translation was replicated in a previous study (Saroglou et al., 2003). For the present study, we selected 18 items (nine items for each dimension) that were found in Saroglou et al. (2003) to have the highest loadings in their factor; the two-factor structure was once again well replicated.

Religion. The same three-item religiosity index as in study 1 was used to measure the importance of God in life, the importance of religion in life, and the frequency of prayer $(\alpha=0.91)$. The one-item index of importance of spirituality in life was also included.

\section{Results}

As detailed in Table 1, distinct by sex bivariate correlations between religion measures and self-reported humour styles revealed first that religious women tended to report low use of hostile and earthy humour. Women's religiousness was not related to the other humour styles. For men, both religiosity and spirituality were negatively related with earthy humour and positively related with

TABLE 1. Coefficients of correlations between religion and humour styles

\begin{tabular}{|c|c|c|c|c|c|c|}
\hline \multirow[b]{2}{*}{ Religion } & \multicolumn{6}{|c|}{ Humour styles } \\
\hline & Social & Coping & Hostile & Earthy & Self-defeating & Competent \\
\hline \multicolumn{7}{|l|}{ Self-ratings } \\
\hline \multicolumn{7}{|l|}{ Men } \\
\hline Religiosity & $-0.15+$ & -0.04 & -0.09 & $-0.22^{\star}$ & $0.26^{\star \star}$ & -0.05 \\
\hline Spirituality & -0.01 & -0.02 & -0.08 & $-0.17^{\star}$ & $0.24^{\star \star}$ & 0.12 \\
\hline \multicolumn{7}{|l|}{ Women } \\
\hline Religiosity & -0.03 & -0.06 & $-0.21^{\star}$ & $-0.15+$ & 0.00 & -0.03 \\
\hline Spirituality & 0.01 & -0.01 & -0.04 & -0.11 & 0.12 & 0.07 \\
\hline \multicolumn{7}{|l|}{ Spouse-ratings } \\
\hline \multicolumn{7}{|l|}{$\mathrm{Men}^{\mathrm{a}}$} \\
\hline Religiosity & $-0.17^{\star}$ & $-0.26^{\star \star}$ & $-0.23^{\star}$ & $-0.32^{\star \star \star}$ & 0.06 & $-0.13+$ \\
\hline Spirituality & -0.07 & -0.10 & -0.07 & $-0.19^{\star}$ & 0.02 & 0.04 \\
\hline \multicolumn{7}{|l|}{ Women ${ }^{\text {b }}$} \\
\hline Religiosity & $-0.14+$ & 0.04 & $-0.32^{\star \star \star}$ & $-0.16+$ & 0.11 & -0.05 \\
\hline Spirituality & -0.08 & 0.04 & $-0.18^{\star}$ & -0.10 & $0.14+$ & 0.10 \\
\hline
\end{tabular}

Note. $n=98$ married couples.

${ }^{a}$ Coefficients of correlations between religion in men and their use of humour as perceived by their wife.

${ }^{\mathrm{b}}$ Coefficients of correlations between religion in women and their use of humour as perceived by their husband. ${ }^{\star} p<0.05 ;{ }^{\star \star} p<0.01 ;{ }^{\star \star \star} p<0.001 ;+p<0.10$ (one-tailed). 
self-defeating humour. In addition, men's religiosity was negatively related to social humour.

A richer pattern was provided when one looks at the peer (spouse)-ratings. Religious men tended to be perceived by their wife as low in hostile and earthy humour but also low in social humour, use of humour as coping, and competent humour. In addition, men's spirituality was also negatively related to their use of earthy humour as evaluated by their wife. Religious and/or spiritual women tended to be perceived by their husband as being low in hostile humour (both religion indexes), earthy and social humour (religiosity), and high in self-defeating humour (spirituality).

It could be suspected that, as married participants were different with regard to their age, the above results may have been influenced by age. For instance, it could be hypothesized that as people become older, they also become more religious and they value or use humour less, although the cross-sectional character of the study does not allow for determining whether such effects should be interpreted as age per se or cohort effects. Consequently, the above results could be an artefact of age. Indeed, age was positively related with religiosity and spirituality of men $(r s=0.30, p<0.01 ; 0.21, p<0.05)$ and women $(r s=0.23,0.17$, $p<0.05)$. Besides, older men tended to report low use of social $(r s=-0.26$, $p<0.01)$ and earthy $(r s=-0.25, p<0.05)$ humour, whereas older women tended to report low use of self-defeating humour $(r s=-0.19, p<0.10)$. However, when partial correlations were computed between religion measures and humour styles (both self-reports and spouse-ratings), all of the above results (Table 1) remained significant (with two exceptions: the associations between men's spirituality and their reported self-defeating humour, and between women's religiosity and their social humour as perceived by husbands were no longer significant). Some additional results were observed: women with high spirituality tended to report using self-defeating humour $(r=0.15, p<0.10)$, and religiosity of men was followed by the use of self-defeating humour in their wife's perception $(r=0.14$, $p<0.10$ ).

In order to understand the association between religion and self-defeating humour, we investigated the possible impact of insecure attachment. The use of self-defeating humour was positively associated with both anxious $(r=0.37$, $p<0.001)$ and avoidant $(r=0.27, p<0.01)$ attachment in men but not in women. In addition, only in men, religiosity, but not spirituality, was positively related to anxiety and avoidance (respective $r s=0.21,0.25, p<0.05$ ). We thus computed a multiple regression analysis of anxiety, avoidance, and religiosity on men's self-reported use of self-defeating humour. It turned out that anxiety was the most important predictor of men's self-defeating humour $(B=0.27, t=2.66, p<0.01)$, and that religion still had a-marginal-impact $(B=0.17, t=1.74, p<0.10)$, whereas avoidance was no longer a significant predictor.

Finally, we investigated whether religiosity and spirituality of spouses were related to between-partner similarity in the different humour styles. As detailed in Table 2, both men and women who attributed high importance to spirituality also tended to be similar in their use of social humour, and both men and women 
TABLE 2. Coefficients of correlations between religion and absolute difference between spouses in humour styles (self-reports)

\begin{tabular}{llllllr}
\hline & \multicolumn{5}{c}{ Humour styles } \\
\cline { 2 - 6 } Religion & Social & Coping & Hostile & Earthy & Self-defeating & Competent \\
\hline Men & & & & & \\
Religiosity & -0.08 & -0.08 & $-0.14+$ & $-0.15+$ & 0.03 & 0.10 \\
$\quad$ Spirituality & $-0.18^{\star}$ & -0.06 & -0.08 & $-0.19^{\star}$ & 0.00 & 0.02 \\
Women & & & & & & $-0.16+$ \\
$\quad$ Religiosity & -0.11 & -0.12 & -0.02 & $-0.20^{\star}$ & -0.09 \\
Spirituality & $-0.22^{\star}$ & $-0.19^{\star}$ & 0.01 & -0.07 & -0.12 & -0.11 \\
\hline
\end{tabular}

Note. $N=98$ married couples.

${ }^{\star} p<0.05 ;+p 0.10$ (one-tailed).

with high religiosity (and spirituality for men) tended not to differ in their level of earthy humour. In addition, between-spouse similarity in hostile humour was related to religiosity of men, and between-spouse similarity in the use of earthy and coping humour was related respectively to women's religiosity and spirituality.

\section{Discussion}

The results constitute a weak and unsystematic yet appreciable and meaningful support to the hypothesis of a negative association between religion and many humour styles. As predicted, religiosity for both men and women, and spirituality for men was followed by a low use of earthy humour, measured both by self- and peer-ratings. Also as predicted, although less systematically across measures and studies, when results were significant, religious and/or spiritual men and women tended to report or to be perceived as not using hostile humour. The above results taken together may be understood as resulting from the prosocial character of religious personality as well as the spirit of purity and cleanliness, and the non-transgressive character of religion with regard to taboos.

Also in conformity with what was hypothesized, evidence suggested that religious people make little use of humour in general, if we assume in line with previous research (Craik et al., 1996; Martin et al., 2003; Ruch, 1994) that social humour and coping humour reflect mainly overall sense/use of humour, and that self-enhancing humour (in students' sample) is equivalent to the use of humour as coping (in married couples' sample). These findings could be interpreted as due to an overall 'discomfort' of religion with humour. However, this pattern of findings was limited to adults and did not concern the students' sample, probably because their religiosity is known not to imply low extraversion (see studies reviewed in Saroglou, 2002c), the most important personality dimension typical of the overall sense/use of humour (Ruch, 1994). 
(An alternative interpretation could be that since age was negatively related to humour, students' religiosity was lower and so less predictive of external constructs such as humour than adults' religiosity). In addition, the associations were clearer in peer (spouse)-perceptions of husbands and wives' humour than in partners' self-reports, probably because of the socially desirable character of perceiving oneself as humorous.

Moreover, as expected, no association was found between competence in humour and religion measures, a finding that can be understood in light of the fact that religion seems to be unrelated to intelligence (Francis, 1998). However, and unexpectedly, we found, on the basis of bivariate correlations and/or partial correlations controlling for age, that in married couples but not students, husbands clearly, and wives to some extent, tended to report and be perceived as using self-defeating humour as far as they scored high in religion measures. As insecurity in attachment (mainly anxiety) was both characteristic of religious husbands and of people using self-defeating humour (for the latter, see also Saroglou \& Scariot, 2002), it could be that religious men tend to use selfdefeating humour partly because they are insecure in attachment. Indeed, the association between religion and self-defeating humour, when controlling for anxiety and avoidance in partial correlations, decreased from 0.26 to 0.18 . As religion still seemed to explain some variance, it could be that religious husbands who tend to be insecure in attachment use self-disparaging humour in order to increase the quality of their relationship without being preoccupied by the fact that this 'self-humiliation' is contrary to masculine stereotypes about the high status and power of men: there is some evidence, for instance, that religiosity in men is associated with femininity (for example, Thompson, 1991; Francis \& Wilcox, 1996).

Finally, religiosity and/or spirituality of men was found to be negatively related to between-spouse dissimilarity in the use of earthy, social, and hostile humour, whereas religiosity and/or spirituality of women was negatively related to between-spouse dissimilarity in earthy, self-defeating, social, and coping humour. It might be that religious people tend to select for marriage and stay with partners who share among other things similar ways of being amused, for instance through humour, because these ways reflect specific values with respect to order (earthy humour), respect of others (hostile humour), and seriousness in dealing with life problems (social and coping humour) and existential questions (macabre humour). Previous evidence suggests that married partners mainly resemble each other in Openness to Experience (rather than the other dimensions of the Big Five), which includes open-mindedness and openness to values (McCrae, 1996); that common religious affiliation and common beliefs and values play an important role on the choice of partner and the quality or duration of the marriage (Koenig et al., 2000; Medling \& McCarrey, 1981); and that social and self-enhancing humour or use of humour as coping (Martin et al., 2003; McCrae \& Costa, 1986; Saroglou \& Scariot, 2002) as well as earthy humour (Craik \& Ware, 1998) and cheerfulness in general (Ruch \& Köhler, 1998) are positively related to Openness to Experience. 
Two limitations of the present study are the use of simple religion indexes rather than multi-item scales as well as the non-distinction between different religious dimensions. Nevertheless, with regard to the first limitation, a series of studies support the idea that such indexes may also be used and have similar predictive validity to multi-item religiosity scales. The distinction between different religious dimensions could be a question for further research. For instance, one would expect the use of humour in general or the use of specific humour styles to be different for people high or low in religious/spiritual maturity and religious/spiritual well-being. To take another example, religious fundamentalists, known to be high in authoritarianism and authoritarian aggression (Altemeyer, 1996), may use hostile humour, at least when they direct it towards specific others.

In conclusion, being religious seems to imply some difference in humour. Of course, caution is required to avoid generalizing or overstating that religion implies lack of humour. However, if we consider that, except the self-defeating humour that seems to be used frequently by religious men, a negative association seems to exist between religion and the use (present study) or appreciation (Saroglou, 2003) of several humour styles, the question remains: which are these humour styles that are valued, appreciated and exercised by religious people?

\section{Acknowledgements}

Many thanks to Christelle Lacour, Isabelle Roskam, and Christel Scariot for their help with data collection and to Robert Hogenraad for his helpful comments to the manuscript.

\section{References}

Altemeyer, B. (1996). The authoritarian specter. Cambridge: Harvard University Press.

Batson, C.D., Schoenrade, P. \& Ventis, W.L. (1993). Religion and the individual: A social-psychological perspective. New York: Oxford University Press.

Berger, P.L. (1997). Redeeming laughter: The comic dimension of the human experience. New YorkBerlin: Walter de Gruyter.

Brennan, K.A., Clark, C.L. \& Shaver, P.R. (1998). Self-report measurement of adult attachment: An integrative overview. In J.A. Simpson \& W.S. Rholes (Eds.), Attachment theory and close relationships (pp. 46-76). New York: Guilford Press.

Craik, K.H. \& WARE, A.P. (1998). Humor and personality in everyday life. In W. Ruch (Ed.), The sense of humor: Explorations of a personality characteristic (pp. 63-94). Berlin, Germany: Mouton de Gruyter.

Craik, K.H., Lampert, M.D. \& Nelson, A.J. (1996). Sense of humor and styles of everyday humorous conduct. In W. Ruch (Ed.), Measurement approaches to the sense of humor (special issue). Humor: International fournal of Humor Research, 9, 273-302.

Diener, E., Suh, E.M., LuCAS, R.E. \& SMiTh, H.L. (1999). Subjective well-being: Three decades of progress. Psychological Bulletin, 125, 276-302.

Eysenck, M.W. (1998). Personality and the psychology of religion. Mental Health, Religion and Culture, 1, 11-19. 
Fraley, R.C., Waller, N.G. \& Brennan, K.A. (2000). An item response theory analysis of self-report measures of adult attachment. Fournal of Personality and Social Psychology, 78, 350-365.

FRANCIS, L.J. (1998). The relationship between intelligence and religiosity among 15-16-year-olds. Mental Health, Religion and Culture, 1, 185-196.

Francis, L.J., \& Wilcox, C. (1996). Religion and gender orientation. Personality and Individual Differences, 20, 119-121.

GiLhus, I.S. (1997). Laughing Gods, weeping virgins: Laughter in the history of religion. London: Routledge.

Granqvist, P. \& Hagekull, B. (1999). Religiousness and perceived childhood attachment: Profiling socialized correspondence and emotional compensation. Fournal for the Scientific Study of Religion, 38, 254-273.

Hyers, C. (1996). The spirituality of comedy: Comic heroism in a tragic world. New Brunswick, NJ: Transaction Publishers.

KiRKPATRICK, L.A. (1999). Attachment and religious representations and behavior. In J. Cassidy \& P.R. Shaver (Eds.), Handbook of attachment: Theory, research, and clinical applications (pp. 803-822). New York: Guilford Press.

Koenig, H.G., McCullough, M.E. \& Larson, D.B. (2000). Handbook of religion and health. New York: Oxford University Press.

KöHLER, G. \& RUCH, W. (1996). Sources of variance in current sense of humor inventories: How much substance, how much method variance? Humor: International fournal of Humor Research, 9, 363-397.

Kuschel, K.-J. (1994). Laughter: A Theological essay. London: SCM Press.

Lewis, C.A. (1998). Cleanliness is next to godliness: Religiosity and obsessiveness. Fournal of Religion and Health, 37, 49-61.

Lewis, C.A. (2000). The religiosity-psychoticism relationship and the two factors of social desirability: A response to Michael W. Eysenck (1999). Mental Health, Religion and Culture, 3, 39-45.

Martin, R.A., \& LefCourt, H.M. (1983). Sense of humor as a moderator of the relation between stressors and moods. Fournal of Personality and Social Psychology, 45, 1313-1324.

Martin, R.A., Puhlik-Doris, P., Larsen, G., Gray, J. \& Weir, K. (2003). Individual differences in uses of humor and their relation to psychological well-being: Development of the Humor Styles Questionnaire. Fournal of Research in Personality, 37, 48-75.

McCrae, R.R. (1996). Social consequences of experiential openness. Psychological Bulletin, 120, 323-337.

McCrae, R.R. \& Costa, P.T., Jr. (1986). Personality, coping, and coping effectiveness in adult sample. Fournal of Personality, 34, 385-405.

Medling, J.M. \& McCarrey, M.W. (1981). Marital adjustment over segments of the family life cycle: The issue of spouses' value similarity. Fournal of Marriage and the Family, 43, 195-203.

Ruch, W. (1992). Assessment of appreciation of humor: Studies with the 3 WD humor test. In Ch. D. Spielberg \& J.N. Butcher (Eds.), Advances in Personality Assessment (Vol. 9, pp. 27 75). Hillsdale, NJ: Erlbaum.

Ruch, W. (1994). Temperament, Eysenck's PEN system, and humor related traits. Humor: International fournal of Humor Research, 7, 209-244.

Ruch, W. \& KöHLER, G. (1998). A temperament approach to humor. In W. Ruch (Ed.), The sense of humor: Explorations of a personality characteristic (pp. 203-228). Berlin, Germany: Mouton de Gruyter.

SARoglou, V. (2002a). Religion and sense of humour: An a priori incompatibility? Theoretical considerations from a psychological perspective. Humor: International fournal of Humor Research, 15, 191-214.

Saroglou, V. (2002b). Religiousness, religious fundamentalism, and quest as predictors of humor creation. International fournal for the Psychology of Religion, 12, 177-188. 
SARoglou, V. (2002c). Religion and the five factors of personality: A meta-analytic review. Personality and Individual Differences, 32, 15-25.

SAROGLOU, V. (2003). Humor appreciation as function of religious dimensions. Archiv für Religionpsychologie, 24, 144-153.

SARoglou, V. \& Fiasse, L. (2003). Birth order, personality and religion: A study among young adults from a three-sibling family. Personality and Individual Differences, 35, 19-29.

SARoglou, V. \& JASPARD, J.-M. (2001). Does religion affect humour creation? An experimental study. Mental Health, Religion, and Culture, 4, 33-46.

SARoglou, V. \& LAcour, C. (2003). Partners' humor styles, attachment and marital satisfaction. Manuscript submitted for publication.

SARoglou, V. \& Scariot, C. (2002). Humor Styles Questionnaire: Personality and educational correlates in Belgian high school and college students. European fournal of Personality, 16, 43-54.

Saroglou, V., Kempeneers, A. \& Seynhaeve, I. (2003). Need for closure and adult attachment dimensions as predictors of religion and reading interests. In J. Corveleyn, P. Roelofsma \& J. van Saane (Eds.), One hundred years of psychology and religion (pp. 139-154). Amsterdam: VU University Press.

Schwartz, S.H. \& Huismans, S. (1995). Value priorities and religiosity in four western religions. Social Psychology Quarterly, 58, 88-107.

Simonton, D.K. (2002). Creativity. In C.R. Snyder \& S.J. Lopez (Eds.), Handbook of positive psychology (pp. 189-201). London: Oxford University Press.

Thompson, E.H., Jr. (1991). Beneath the status characteristic: Gender variations in religiousness. Fournal for the Scientific Study of Religion, 30, 381-394.

Thorson, J.A. \& Powell, F.C. (1993). Development and validation of a multidimensional sense of humor scale. Fournal of Clinical Psychology, 49, 13-23.

Trimble, D.E. (1997). The Religious Orientation scale: Review and meta-analysis of social desirability effects. Educational and Psychological Measurement, 57, 970-986.

WulfF, D.M. (1997). Psychology of religion: Classic and contemporary (2nd ed.). New York: Wiley \& Sons. 